Case control study

\title{
Risk of upper gastrointestinal bleeding and perforation associated with low-dose aspirin as plain and enteric-coated formulations Francisco $\mathrm{J}$ de Abajo ${ }^{* 1}$ and Luis A García Rodríguez ${ }^{2}$
}

\author{
Address: ${ }^{1}$ División de Farmacoepidemiología y Farmacovigilancia, Agencia Española del Medicamento, Madrid, Spain and ${ }^{2}$ Centro Español \\ de Investigación Farmacoepidemiológica, Madrid, Spain \\ E-mail: Francisco J de Abajo* - fabajo@agemed.es; Luis A García Rodríguez - lagarcia@ceife.es \\ ${ }^{*}$ Corresponding author
}

Published: 13 February 200I

BMC Clinical Pharmacology 200I, I:I

This article is available from: http://www.biomedcentral.com/I472-6904/I/I

(c) 200 I de Abajo and García Rodríguez, licensee BioMed Central Ltd.
Received: 29 November 2000

Accepted: I3 February 200 I

\begin{abstract}
Background: The use of low-dose aspirin has been reported to be associated with an increased risk of upper gastrointestinal complications (UGIC). The coating of aspirin has been proposed as an approach to reduce such a risk. To test this hypothesis, we carried out a population based casecontrol study.

Methods: We identified incident cases of UGIC (bleeding or perforation) aged 40 to 79 years between April 1993 to October 1998 registered in the General Practice Research Database. Controls were selected randomly from the source population. Adjusted estimates of relative risk (RR) associated with current use of aspirin as compared to non use were computed using unconditional logistic regression.

Results: We identified 2,I05 cases of UGIC and selected II,500 controls. Among them, 287 (13.6\%) cases and 837 (7.3\%) controls were exposed to aspirin, resulting in an adjusted RR of 2.0 $(1.7-2.3)$. No clear dose-effect was found within the range of $75-300 \mathrm{mg}$. The RR associated with enteric-coated formulations $(2.3, \quad 1.6-3.2)$ was similar to the one of plain aspirin $(1.9,1.6-2.3)$, and no difference was observed depending on the site. The first two months of treatment was the period of greater risk ( $R R=4.5,2.9-7.1)$. The concomitant use of aspirin with high-dose NSAIDs greatly increased the risk of UGIC $(13.3,8.5-20.9)$ while no interaction was apparent with lowmedium doses $(2.2, \quad 1.0-4.6)$.

Conclusions: Low-dose aspirin increases by twofold the risk of UGIC in the general population and its coating does not modify the effect. Concomitant use of low-dose aspirin and NSAIDs at high doses put patients at a specially high risk of UGIC.
\end{abstract}

\section{Background}

Upper gastrointestinal complications (UGIC) are the major risk associated with aspirin use $[1,2,3,4]$. As with non-aspirin non-steroidal antiinflammatory drugs (NSAIDs), dose appears to be a major determinant, but even with low $(300 / 325 \mathrm{mg})$ or very low doses $(75 \mathrm{mg})$ a residual amount of risk seems to persist $[3,4]$.
It has been postulated that enteric-coated formulations of aspirin, designed to resist the disintegration in acid environment and pass by the stomach without dissolution, may have an impact in reducing the risk [ 5]. The idea behind this strategy is grounded on the belief that gastric damage caused by aspirin is mainly due to a local effect [ 6]. Results from several endoscopic studies car- 
ried out in healthy volunteers supported this hypothesis showing that enteric-coated aspirin caused less gastric erosion and microbleeding than regular formulations $[7,8,9]$. However, it is known that these lesions are not good predictors of major upper gastrointestinal complications. From an epidemiological point of view the question is a matter of controversy as well. Two case-control studies have reported data on the effect of enteric-coated preparations on upper gastrointestinal bleeding, yielding to apparently opposite results. Weil et al [3] concluded that "enteric-coated aspirin ... may be free of risk" after estimating an odds ratio of 1.6 but with a wide $95 \%$ confidence interval (0.5-4.9). On the other hand, Kelly et al [ 4] found a risk of 2.6 (95\% confidence interval, 1.45.3) which was essentially similar to the one estimated for plain aspirin when the effect of dose was taken into account.

In order to shed some light onto this issue and to estimate the specific aspirin-related risk of upper gastrointestinal bleeding and perforation, its relation with dose and duration of treatment, as well as the potential interaction between aspirin and other drugs (particularly NSAIDs), we used data from a case-control study designed to estimate risks of UGIC associated with drugs and other factors [10].

\section{Subjects and methods}

A case-control study was carried out using data from the UK-based General Practice Research Database. This database has been described extensively elsewhere [11]. Briefly, it contains details of patients' demographics, medical diagnosis, referrals to consultants and hospitals, and prescriptions. The accuracy and completeness of these data have been validated in previous studies [12].

\section{Case definition and ascertainment}

The source population was encompassed by patients aged 40 to 79 years between April 1993 and October 1998, with at least 2 years' enrollment with their general practitioner. Patients with cancer, oesophageal varices, Mallory-Weiss disease, alcoholism, liver disease, or coagulopathies were excluded. We identified incident cases of upper gastrointestinal bleeding or perforation, and reviewed their computerised profiles. The date of first diagnosis was used as the index date. Patients with any of the exclusion criteria mentioned above in the 2 months after index date, those discharged from hospital in the two previous weeks, and subjects with the source of the bleed/perforation in the oesophagus or lower gastrointestinal tract were not retained as cases. A patient was considered a case of UGIC when no exclusion criterion was found, and the specific site of bleed/perforation was located in the stomach or duodenum or the clinical diag- nosis was peptic ulcer. Only patients referred to a specialist or admitted to hospital were retained as cases. To confirm the validity of our computer-based case ascertainment, we requested from the general practitioners a copy of the paper-based records of 100 randomly sampled patients. We received records for 99 patients of which 98 were confirmed as cases. We therefore decided to study all patients classified as cases on the basis of the review of computerised information [13]. Patients with a fatal outcome within a month of the beginning of the episode were considered as fatal cases.

\section{Control selection}

All patients from the source population were assigned a random date during the study period. If such random date fell within his/her observation period, that patient was considered eligible as control. From this population we randomly selected 11,500 patients frequencymatched with cases for age (interval of 1 year), sex and calendar year. We applied to controls the same exclusion criteria used for cases [14].

\section{Exposure definition}

We defined patients as "current users" when the supply of a prescription for aspirin lasted until the index date or ended within the period of 30 days before index date, "recent users" when the supply ended between 31 to 180 days before the index date, "past users" if the supply ended more than 180 days before and "non-users" if no prescription was ever recorded before the index date. Among current and recent use categories we also explored narrower exposure windows. Among current users, we studied the effect of dose, treatment duration and formulation of aspirin. For the estimation of daily dose two different approaches were followed: 1 ) the dose instructed by the general practitioner and 2) the average dose calculated by dividing the number of tablets supplied (provided that at least three prescriptions were written before index date) over the treatment period. Although a wide range of different strengths of low-dose aspirin are available in the U.K., the most widely used by general practitioners are $75 \mathrm{mg}$ and $300 \mathrm{mg}$. A number of physicians prescribed a $300 \mathrm{mg}$ tablet to be taken in alternate days; from a risk perspective, we considered such patients closer to the $300 \mathrm{mg}$ group and were included in this category. Duration of treatment was calculated by adding up the time corresponding to consecutive prescriptions of aspirin before the index date, considering two prescriptions as consecutive when the interval between the end of supply of one prescription and the start of the next one was less than 120 days (this interval was meant to make a clear separation between those patients actually starting a new treatment course with aspirin from those having a poor compliance). Further, among current users we distinguished 
between those patients whose aspirin treatment course was the first ever recorded in the GPRD over the study period, and those with a previous (or distant) use. The indication of aspirin was studied among current users in two random samples of 100 subjects each among cases and controls. All manual review was done blinded to the status of each patient (case or control).

We also evaluated the exposure to other drugs such as non-aspirin NSAIDs, paracetamol, steroids, anticoagulants, selective serotonin reuptake inhibitors and antiulcer drugs (antacids, H2-blockers and omeprazol). Among current users of NSAIDs, we distinguished between low-medium and high daily doses using the cutoff limits described in previous studies [10].

Table I: Distribution of study population by sex and age group

\begin{tabular}{lll}
\hline & $\begin{array}{l}\text { Cases } \\
(\mathrm{N}=2,105)\end{array}$ & $\begin{array}{l}\text { Controls } \\
(\mathrm{N}=1 \mathrm{I}, 500)\end{array}$ \\
\hline $\begin{array}{l}\text { Gender } \\
\text { Male }\end{array}$ & $\mathrm{I}, 327(63.0 \%)$ & $7,167(62.3 \%)$ \\
$\begin{array}{l}\text { Age group } \\
40-59\end{array}$ & $667(31.7 \%)$ & $3,766(32.8 \%)$ \\
$60-69$ & $627(29.8 \%)$ & $3,392(29.5 \%)$ \\
$70-79$ & $811(38.5 \%)$ & $4,342(37.8 \%)$ \\
\hline
\end{tabular}

\section{Analysis}

We used unconditional logistic regression to compute adjusted estimates of relative risk and 95\% confidence intervals (95\% CI) for current use of aspirin as compared to non-use. Two different outcomes were studied: upper gastrointestinal bleeding (UGIB) and perforation. The location of the lesion was considered in the analysis when number of cases allowed for that. Also, we examined separately fatal cases. The following covariates were studied as potential confounders: history of upper gastrointestinal disorder (dyspepsia, peptic ulcer, upper gastrointestinal bleeding/perforation), smoking status (information available for $84 \%$ of study population), alcohol consumption (information available for $58 \%$ of study population), and current use of drugs related with an increased risk of upper gastrointestinal complications: non-aspirin NSAIDs [15], anticoagulants, corticosteroids [15], high-dose ( $>2$ grams) paracetamol [10] and selective serotonin reuptake inhibitors [16]. The matching factors were included in the model as well. We studied the interaction between aspirin and other drugs by forming one single term in the model for the joint effect. The relative excess risk due to interaction (RERI) was used as a measure of interaction and was calculated as: Relative risk (current joint use of "a" and "b")-relative risk (current use of "a" only)- relative risk (current use of "b" only) + 1, being "a" and "b" the factors whose interaction is being studied $[17,18]$.

Table 2: Risk of UGIB and perforation associated with aspirin use

\begin{tabular}{|c|c|c|c|}
\hline & $\begin{array}{l}\text { All cases } \\
(\mathrm{N}=2,105)\end{array}$ & $\begin{array}{l}\text { Controls } \\
(N=11,500)\end{array}$ & $\begin{array}{l}\text { Adjusted RR* } \\
(95 \% \mathrm{Cl})\end{array}$ \\
\hline Non-use & 1,696 & 10,157 & I (reference) \\
\hline Current use $(I-30)$ & 287 & 837 & $2.0(1.7-2.3)$ \\
\hline $\begin{array}{l}\text { Use within I-7 } \\
\text { days time window }\end{array}$ & 259 & 771 & $2.0(1.7-2.3)$ \\
\hline $\begin{array}{l}\text { Use within 8-30 } \\
\text { days time window }\end{array}$ & 28 & 66 & $2.3(1.4-3.7)$ \\
\hline Recent use $(31-180)$ & 37 & 123 & $1.5(1.0-2.3)$ \\
\hline $\begin{array}{l}\text { Use within } 31-60 \\
\text { days time window }\end{array}$ & 14 & 45 & $1.7(0.9-3.3)$ \\
\hline $\begin{array}{l}\text { Use within } 61-180 \\
\text { days time window }\end{array}$ & 23 & 78 & $1.5(0.9-2.5)$ \\
\hline Past use $(>180)$ & 85 & 383 & I.I (0.8-1.4) \\
\hline
\end{tabular}

\footnotetext{
* Adjusted for sex, age, calendar year, antecedents of gastrointestinal disorders, smoking status, alcohol consumption and use of NSAIDs, anticoagulants, steroids, SSRIs and paracetamol.
}

\section{Results}

We identified 1,833 cases of upper gastrointestinal bleeding and 272 cases of perforation. Cases and controls did not differ by age group and sex (table 1). Among bleeding cases, the lesion was located at the stomach in $764(42 \%)$ and the duodenum in 811 (44\%), remaining unspecified in $258(14 \%) ; 4.1 \%$ of bleeding cases were fatal. Among perforation cases, 36 (13\%) were located in the stomach and $236(87 \%)$ in the duodenum with a case-fatality rate of $21.0 \%$. Two hundred eighty seven cases $(13.6 \%)$ of upper gastrointestinal bleeding ( $n=$ $248 ; 13.5 \%)$ or perforation $(n=39 ; 14.3 \%)$ were current users of aspirin, as compared to 837 current users among controls (7.3\%) yielding to an adjusted RR of 2.0 (95\% CI: 1.7-2.3) for all cases (table 2). No material difference was found when upper gastrointestinal bleeding (2.0, 1.7-2.4) and perforation $(1.7,1.2-2.6)$ were considered as separate outcomes, or when location was taken into account (gastric 2.0, 1.6-2.5; duodenal 1.7, 1.4-2.1). The risk was essentially the same either for fatal (1.8, 1.1-2.9) or nonfatal $(2.0,1.7-2.4)$ cases. No modification of the relative risk estimates was observed by sex (males, 2.0 (1.6-2.4); females, $2.0(1.5-2.6)$. The relative risks by age group were as follows: 40-59 years, 2.4 (1.3-4.4); 60-69 years, 2.3 (1.8-3.1); 70-79 years, 1.8 (1.4-2.2). 
The indications for aspirin among a random sample of 100 cases were secondary prevention of coronary heart disease (47), secondary prevention of cerebrovascular ischaemic events (36), peripheral vascular disease (5), other cardiovascular disease (2), and analgesia (2). For the remainder (8) the indication was not unequivocally identified from the patient profiles. The distribution of indications in a random sample of 100 controls was 50 , $30,5,3,2$ and 10, respectively.

Table 3: Relation between aspirin dose and risk of UGIB and perforation among current users as compared to non-use

$\begin{array}{lll}\text { All cases } & \text { Controls } & \text { Adjusted RR* } \\ (\mathrm{N}=2,105) & (\mathrm{N}=11,500) & (95 \% \mathrm{Cl})\end{array}$

\begin{tabular}{llll}
$\begin{array}{l}\text { Daily dose as instructed } \\
75 \mathrm{mg}\end{array}$ & \multicolumn{1}{l}{} & & \\
$150 \mathrm{mg}$ & 84 & 420 & $1.9(1.6-2.4)$ \\
$300 \mathrm{mg} \$$ & 54 & 245 & $2.0(1.5-2.6)$ \\
$600+\mathrm{mg}$ & 8 & 9 & $2.0(1.4-2.8)$ \\
Average daily dose + & & & $4.0(1.4-11.5)$ \\
$<50 \mathrm{mg}$ (irregular use) & 4 & 29 & $0.7(0.2-2.0)$ \\
$51-111$ & 135 & 383 & $2.1(1.7-2.6)$ \\
$112-225$ & 91 & 258 & $1.9(1.5-2.5)$ \\
$226-400$ & 48 & 151 & $2.0(1.4-2.9)$ \\
$>400$ & 9 & 16 & $3.1(1.3-7.5)$
\end{tabular}

* Adjusted for sex, age, calendar year, antecedents of gastrointestinal disorders, smoking status, alcohol consumption and use of NSAIDs, anticoagulants, steroids, SSRIs and paracetamol. Additional adjustment for use of antiulcer drugs (antacids, H2-blockers and omeprazol) did not change the estimates. \$ Five cases and three controls taking 300 $\mathrm{mg}$ in alternate days were included in this category. Assigning those patients to the 150-mg category hardly modified the results. + Calculated by dividing the number of tablets supplied over the treatment period. For $16 \mathrm{I}$ patients (5I (18\%) cases and II0 (13\%) controls) less than 3 prescriptions of aspirin were written, therefore the instructed dose was still considered in these patients.

Seventy-five mg was the daily dose most frequently prescribed (48\%) in controls, followed by $150 \mathrm{mg}(27 \%)$, $300 / 325 \mathrm{mg}(19 \%)$, and more than $325 \mathrm{mg}$ (6\%). No dose-effect relation was observed with aspirin within the 75-300 $\mathrm{mg}$ range according to the instructions written by the general practitioner (table 3 ). This remained true when the analysis was restricted to a specific lesion (either bleeding or perforation) or to a specific location (either gastric or duodenal) (see additional material: Appendix 1). Results did not materially change when only patients without any antecedents of gastrointestinal disorders (including dyspepsia) were considered (see additional material: Appendix 2), or when we controlled for use of antiulcer drugs. For 149 patients (45 (16\%) cases and 104 (12\%) controls) among current users the average daily dose estimated through the number of tab- lets supplied exceeded the cut-off values established to separate different dose categories $(112,225$ and 400 $\mathrm{mg}$ ). The replacement of the "instructed dose" by the average dose did not make a significant change (table 3). Nor did the restriction of the analysis to patients with consistent data for both methods of aspirin dose assessment.

Enteric-coated aspirin was associated with a risk of UGIC (RR of 2.3, 1.6-3.2) similar to the one of plain aspirin (1.9, 1.6-2.3). Estimates hardly changed when analysing separately bleeding and perforation, or gastric and duodenal sites (table 4). As enteric-coated aspirin could have been prescribed preferentially for those patients at greater risk of gastrointestinal damage, we performed a sub-analysis including only individuals without any antecedent of upper gastrointestinal disorder: the relative risk estimate for enteric-coated aspirin was 2.7 (1.7-4.2) and the one for plain aspirin was 2.2 (1.8-2.8). The results did not change when additional adjustment for antiulcer drugs use was performed. Estimates of risk associated with aspirin formulation and stratified by dose are shown in table 5 . We observed a dose-response starting at $300 \mathrm{mg}$ with plain aspirin but could not find a similar pattern with enteric-coated.

Table 4: Risk of UGIB and perforation associated with aspirin use according to location, type of lesion and aspirin formulation

Adjusted* RR $(95 \% \mathrm{Cl})$

All cases UGIB Perforation

$\begin{array}{lllll}\text { All sites } & \text { Plain } & 1.9(1.6-2.3) & 2.0(1.6-2.4) & 1.6(1.1-2.5) \\ & \text { Coated } & 2.3(1.6-3.2) & 2.2(1.5-3.2) & 2.4(1.1-5.0) \\ \text { Gastric } & \text { Plain } & 2.0(1.5-2.5) & 2.0(1.6-2.6) & -\$ \\ & \text { Coated } & 2.2(1.4-3.6) & 2.3(1.4-3.8) & \\ \text { Duodenal } & \text { Plain } & 1.6(1.3-2.1) & 1.5(1.2-2.0) & 1.8(1.1-2.8) \\ & \text { Coated } & 2.2(1.4-3.4) & 1.9(1.1-3.2) & 2.9 \#(I .4-6.1)\end{array}$

* Adjusted for sex, age, calendar year, antecedents of gastrointestinal disorders, smoking status, alcohol consumption and use of NSAIDs, anticoagulants, steroids, SSRIs and paracetamol \$Only 3 cases of gastric perforation exposed to plain aspirin and none to coated aspirin \# Based on 9 exposed cases and 142 controls

As shown in table 6, the duration of treatment had an impact upon the risk of upper gastrointestinal complication, being the first two months of use the period of greater risk $(4.5,2.9-7.1)$. Such a pattern was observed across different doses (table 7) or formulations of aspirin (see additional material: Appendix 3), though it was less sharp within the $75 \mathrm{mg}$ dose and for enteric-coated preparations. The indication for aspirin in those patients 
with shorter treatment duration (less than 2 months) was related to cardiovascular disorders in $88 \%$ of cases and $89 \%$ of controls. Among short-term users, those who used aspirin for the first time appeared to be at the same relative risk as those with a previous non-consecutive prescription of aspirin ("distant use") (table 6). The initial increased risk was clearly observed for bleeding lesions and less markedly for perforation (see additional material: Appendix 4).

Table 5: Effect of aspirin formulation and dose on risk of UGIB and perforation among current users as compared to non-use

\begin{tabular}{|c|c|c|c|}
\hline & $\begin{array}{l}\text { All cases } \\
(\mathrm{N}=2,105)\end{array}$ & $\begin{array}{l}\text { Controls } \\
(N=\mid I, 500)\end{array}$ & $\begin{array}{l}\text { Adjustec } \\
\mathrm{RR}^{*} \\
(95 \% \mathrm{Cl})\end{array}$ \\
\hline \multicolumn{4}{|c|}{ Formulation/dose as instructed } \\
\hline \multicolumn{4}{|c|}{ Plain } \\
\hline$\leq 150 \mathrm{mg}$ & 201 & 626 & $\begin{array}{l}1.9(1.6- \\
2.2)\end{array}$ \\
\hline $300+m g$ & 30 & 69 & $\begin{array}{l}2.6(1.6- \\
4.2)\end{array}$ \\
\hline \multicolumn{4}{|c|}{ Enteric-coated } \\
\hline$\leq 150 \mathrm{mg}$ & 24 & 39 & $\begin{array}{l}3.5(2.0- \\
6.1)\end{array}$ \\
\hline $300+m g$ & 32 & 103 & $\begin{array}{l}1.8(1.2- \\
2.8)\end{array}$ \\
\hline
\end{tabular}

* Adjusted for sex, age, calendar year, antecedents of gastrointestinal disorders, smoking status, alcohol consumption and use of NSAIDs, anticoagulants, steroids, SSRIs and paracetamol. Additional adjustment for antiulcer drugs use did not change the estimates.

The concomitant use of aspirin together with other nonaspirin NSAIDs at high dose increased substantially the risk of major UGIC (relative risk 13.3, 8.5-20.9), far beyond the sum of their respective independent effects (RERI=7.9, 2.0-13.8), while no interaction was apparent when low-dose aspirin was taken together with NSAIDs at low-medium dose (RR of 2.2, 1.0-4.6) (table 8). The interaction appeared to be greater for perforation $(\mathrm{RR}=30.3,15.0-61.3$; RERI=23.1, 2.2-44.2) than for bleeding $\quad(\mathrm{RR}=10.8,6.6-17.5 ; \mathrm{RERI}=5.7,0.5-10.9)$. Among bleeding lesions no difference was found between the relative risk of the combination for those located at the stomach $(R R=12.2,6.8-21.9)$ and those located at the duodenum (14.3, 8.3-24.5). Both formulations of aspirin presented this interaction with high-dose NSAIDs (plain, 12.7 (7.7-20.8); enteric-coated, 16.6 $(5.9-46.3)$. No relevant interaction beyond the sum of the independent effects was observed between aspirin and high-dose paracetamol $(4.5,1.9-10.9)$ or aspirin and steroids (1.9, 0.9-3.8). A small interaction was observed between low-dose aspirin and anticoagulants (5.5, 2.412.7).

Table 6: Effect of duration of treatment with aspirin on the risk of UGIB and perforation among current users as compared to nonuse

$\begin{array}{lll}\text { All cases } & \text { Controls } & \begin{array}{l}\text { Adjusted } \\ \text { RR* } \\ \end{array} \\ (\mathrm{N}=2,105) & (\mathrm{N}=1 \mathrm{I}, 500) & (95 \% \mathrm{Cl})\end{array}$

$\begin{array}{lccl}\begin{array}{l}\text { Days of treatment } \\ \text { (consecutive prescriptions) }\end{array} & & & \\ \text { I-60 (all users) } & 40 & 52 & \begin{array}{l}4.5(2.9- \\ 7.1)\end{array} \\ \text { First-ever users } & 25 & 32 & \begin{array}{l}4.6(2.7- \\ 8.1)\end{array} \\ \text { Distant users } & 15 & 20 & \begin{array}{l}4.2(2.0- \\ 8.6)\end{array} \\ 61-180 & 34 & 71 & \begin{array}{l}2.7(1.7- \\ 4.2)\end{array} \\ 181-730 & 96 & 286 & \begin{array}{l}1.9(1.5- \\ 2.5)\end{array} \\ >730 & & & 1.6(1.3- \\ & 117 & 428 & 2.0)\end{array}$

*Adjusted for sex, age, calendar year, antecedents of gastrointestinal
disorders, smoking status, alcohol consumption and use of NSAIDs,
anticoagulants, steroids, SSRIs and paracetamol. Additional adjustment
for antiulcer drugs use did not change the estimates.

\section{Discussion}

The results of the present study show that the use of lowdose aspirin for prophylaxis of cardiovascular disorders conveys a twofold increased risk of upper gastrointestinal bleeding and perforation in the general population. This increased risk is found over different categories of age and sex. The effect of aspirin applies equally to gastric and duodenal sites.

We did not find a clear relation with aspirin daily dose within the range $75-300 \mathrm{mg}$. Such a result did not change when we restricted the analysis to patients without any antecedent of upper gastrointestinal disorder or when we adjusted for use of antiulcer drugs. This reasonably excludes a potential selection of patients with a greater risk of UGIC to lower doses of aspirin. Looking for other sources of bias, we identified that in $13 \%$ of patients the dose instructed by the general practitioner was not consistent with the average daily dose calculated by counting the number of tablets supplied. We tried to correct this by restricting the analysis to the population having consistent data with both methods and by replacing the instructed dose by the average. Neither of those corrections yielded different results. Nevertheless, a suggestion of a greater risk associated with aspirin at higher 
doses within the range $75-300 \mathrm{mg}$ versus lower doses was found among users of the plain formulation and among short-term users (first 60 days of treatment). Finally, although the confidence intervals for lower doses are reasonably narrow, some statistical uncertainty remains and a dose-effect cannot be excluded; therefore, the use of the lowest dose shown effective is still the best strategy to minimise risk.

Table 7: Effect of duration of treatment with aspirin on the risk of UGIB and perforation among current users as compared to nonuse by aspirin dose

$\begin{array}{lll}\text { All cases } & \text { Controls } & \text { Adjusted RR* } \\ (\mathrm{N}=2,105) & (\mathrm{N}=11,500) & (95 \% \mathrm{Cl})\end{array}$

\begin{tabular}{llll}
$\begin{array}{l}\text { Daily dose as instruct- } \\
\text { ed/ }\end{array}$ & & & \\
$\begin{array}{l}\text { Days of treatment/ } \\
75 \mathrm{mg}\end{array}$ & & & \\
$1-60$ & 17 & 32 & $3.2(1.7-6.1)$ \\
$61-180$ & 20 & 37 & $2.9(1.6-5.2)$ \\
$181-730$ & 53 & 166 & $1.7(1.2-2.5)$ \\
$>731$ & 51 & 185 & $1.7(1.3-4.6)$ \\
$150 \mathrm{mg}$ & & & \\
$1-60$ & 13 & 11 & $6.6(2.7-15.9)$ \\
$61-180$ & 11 & 23 & $2.7(1.2-6.0)$ \\
$181-730$ & 26 & 83 & $2.0(1.2-3.2)$ \\
$>730$ & 34 & 128 & $1.5(1.0-2.2)$ \\
$300+\mathrm{mg}$ & & & \\
$1-60$ & 10 & 9 & $6.0(2.2-16.2)$ \\
$61-180$ & 3 & 11 & $1.9(0.5-7.1)$ \\
$181-730$ & 17 & 37 & $2.6(1.4-4.9)$ \\
$>730$ & 32 & 115 & $1.7(1.1-2.6)$ \\
& & & \\
\hline
\end{tabular}

*Adjusted for sex, age, calendar year, antecedents of gastrointestinal disorders, smoking status, alcohol consumption and use of NSAIDs, anticoagulants, steroids, SSRIs and paracetamol.

The enteric-coated formulations appear not to protect from the aspirin-induced risk of upper gastrointestinal bleeding, irrespective of the dose, neither for gastric nor for duodenal lesions. This observation adds up to previous results from other investigators [4]. Assuming that the coating of aspirin effectively spares the stomach from its topical adverse effect, such results cast doubts on the overall contribution of the local effect in serious bleeding lesions observed among aspirin users. Instead, our findings support the hypothesis that the effect of aspirin, both plain and enteric-coated, on upper gastrointestinal bleeding is mainly systemic mediated through inhibition of platelet thromboxane $A_{2}$ synthesis [19] and/or inhibition of protective prostaglandin synthesis in the gastroduodenal mucosa [20]. A local effect, however, cannot be ruled out as a relevant contributor for aspirininduced perforation, as most cases were located in duo- denum, and no difference or, perhaps, a slightly greater risk was found with the coated formulation. A preferential prescription of enteric-coated aspirin to patients with antecedents of gastrointestinal disorders does not explain our results, since enteric-coated aspirin users with no such antecedents present a risk similar to the one associated with plain aspirin.

Patients in the first two months after starting treatment with aspirin are at the greatest risk of presenting a major UGIC. Thereafter, the risk goes down and reaches a plateau at around six months. This phenomenon has been observed by other researchers for aspirin [3] but remains controversial for other NSAIDs $[10,15]$. It has been suggested that this high hazard rate at the beginning of treatment could be an artefact induced by the use of aspirin for early symptoms of peptic ulcer. This possibility can be reasonably ruled out in our study because almost 90\% of cases who experienced bleeding or perforation early after starting treatment with aspirin were using it for prevention of cardiovascular disorders, a pattern of use identical to the one found for new users among controls. Another explanation argued for the decreasing risk with the continuation of treatment has been the "early withdrawal of population susceptible to damage" [3]. In order to explore this possibility we divided short-term users of aspirin ( $<2$ months) into "distant users" and "first-ever users", depending on the recording or not of a remote non-consecutive prescription for aspirin. We did not find any apparent difference in risk between these two groups. So, patients who stopped treatment with aspirin for whatever reason and then started again after a washout period of at least four months, presented a similar risk during the first two months of treatment as first-ever users. By exclusion, the duration response could be explained by the third mechanism postulated so far: the existence of an adaptation of the gastrointestinal mucosa to the toxic action of aspirin. According to our results, this adaptation process would take at least 2 months to result into clinical benefits. In striking contrast, a constant risk pattern has been found with non-aspirin NSAIDs $[10,15]$. The reasons for such discrepancy are unknown and should be further studied. In our view, the explanation should be searched in the pharmacological differences of aspirin as compared to non-aspirin NSAIDs. It is well known that aspirin has a much greater topical adverse effect on the stomach lining than non-aspirin NSAIDs [21] and perhaps the adaptive process concerns mainly this mechanism of action.

The concurrent use of low-dose aspirin with high-dose NSAIDs increases the risk of UGIC by a factor of 13 . Similar findings have been obtained by others for UGIB [3]. Our results strongly suggest that the combination may 
have a particular impact on the risk of perforation (lower confidence interval of 15). It is important to note that the joint use of low-dose aspirin with high-dose NSAIDs is not unusual. In our random sample of 11,500 controls, the prevalence of this combination was 3 per 1,000 subjects, a small figure in relative terms but large from a public health perspective. On the other hand, it is reassuring that no interaction beyond the sum of their respective effects was observed between aspirin and lowmedium NSAIDs, aspirin and steroids, or aspirin and paracetamol (even when this latter was taken at doses higher than 2 grams a day). Although we detected a slight interaction of low-dose aspirin and anticoagulants, the confidence interval of the estimate is wide and precludes any firm conclusion.

The present study has some limitations. Aspirin prescription is systematically recorded in the GPRD, but its over-the-counter use is only recorded occasionally and this could lead to a misclassification of aspirin exposure. Although misclassification of exposures collected prospectively before the occurrence of the event of interest is usually close to non-differential between cases and controls, we evaluated the extent of the under-recording and the type of misclassification using external data from a recent study that analyzed the risk of peptic ulcer bleeding associated with prophylactic aspirin and was also performed in the UK [3]. The authors interviewed patients aged 60 and over and asked, among other things, information about all prescribed and self-administered drug intake. They found that $27.1 \%$ of cases and $15.9 \%$ of controls reported any use of aspirin in the month before $(16.5 \%$ and $8.3 \%$ respectively reported a regular use). In our study population, the prevalence of aspirin use in the month before was $13.6 \%$ and $7.3 \%$ (18.4\% and $10.3 \%$ among the subjects aged 60 years or older). Interestingly, the case-control ratio of aspirin exposure for the reference study is 1.70 , while the corresponding ratio is 1.86 in our study (1.79 for the older group). These figures suggest that the under-recording of OTC aspirin use in our study is to a major extent non-differential with respect to case status. We performed a sensitivity analysis assuming the worst case of a $50 \%$ misclassification of aspirin users. The "true" crude OR would be 2.3 instead of the 2.1 observed. Therefore, it seems unlikely that the underascertainment of OTC aspirin use could have greatly distorted the estimate of aspirin effect in our study. Other authors have recently reached the same conclusion for OTC NSAIDs [22]. It is conceivable that the potential misclassification of enteric-coated preparations due to their higher price were less important than for the plain ones. This means that the distortion to the null would be weaker for the former preparations, but assuming that the misclassification was non-differential with respect to case status, the im- pact of such difference would be negligible. We also examined the effects of a differential misclassification with respect to case status and only under the unrealistic assumption of a strong differential misclassification selectively affecting the higher doses within the range 75-300 mg of plain preparations, could our results of lack of dose-effect and lack of protective effect of enteric-coated preparations be explained.

Table 8: Effect of concomitant use of aspirin and NSAIDs among current users as compared to non use of either drug (multiple users of NSAIDs were excluded).

\begin{tabular}{|c|c|c|c|}
\hline & $\begin{array}{l}\text { All cases } \\
\text { (UGIB/Perfo- } \\
\text { ration) } \\
(\mathrm{N}=2,105)\end{array}$ & $\begin{array}{l}\text { Controls } \\
(N=\mid 1,500)\end{array}$ & $\begin{array}{l}\text { Adjusted RR* } \\
(95 \% \mathrm{Cl})\end{array}$ \\
\hline $\begin{array}{l}\text { Low-medium-dose } \\
\text { NSAIDs only }\end{array}$ & $83(7 / / 12)$ & 256 & $2.6(2.0-3.4)$ \\
\hline $\begin{array}{l}\text { High-dose\# NSAIDs } \\
\text { only }\end{array}$ & $254(202 / 52)$ & 413 & $4.3(3.6-5.2)$ \\
\hline Only aspirin & $221(201 / 20)$ & 767 & $2.1(1.8-2.5)$ \\
\hline $\begin{array}{l}\text { Aspirin + low-medium- } \\
\text { dose NSAIDs }\end{array}$ & $9(6 / 3)$ & 34 & $2.2(1.0-4.6)$ \\
\hline $\begin{array}{l}\text { Aspirin + high-dose\# } \\
\text { NSAIDs }\end{array}$ & $57(4 \mid / 16)$ & 36 & $\begin{array}{l}13.3(8.5- \\
20.9)\end{array}$ \\
\hline
\end{tabular}

\footnotetext{
*Adjusted for sex, age, calendar year, antecedents of gastrointestinal disorders, smoking status, alcohol consumption and use of anticoagulants, steroids, SSRIs and paracetamol. \# High-dose NSAIDs: Aceclofenac $>100$, acemetacin $>120$, diclofenac $>75$, etodolac $>400$, fenbufen $>900$, fenoprofen $>1200$, flurbiprofen $>150$, ibuprofen $>$ 1200 , indometacin $>75$, ketoprofen $>100$, mefenamic acid $>1000$, tiaprofenic acid $>450$, azapropazone $>600$, meloxicam $>7.5$, nabumetone $>1000$, naproxen $>500$, piroxicam $>10$, sulindac $>200$, tenoxicam $>10$ (all doses in $\mathrm{mg}$ ).
}

We tried to control for other potential sources of bias, including channelling of patients with greater risk to lower-dose or enteric-coated aspirin. However, as with all observational studies, unmeasured or inaccurately measured factors may lead to residual confounding.

\section{Conclusions}

Aspirin used at doses as low as $75 \mathrm{mg}$ is still associated with a moderate risk of developing serious upper gastrointestinal complications. The coating of the active principle in order to spare the stomach does not reduce the risk of upper gastrointestinal complications, neither for the stomach nor for the duodenum. The first two months of treatment seem to be the period of greater risk, regardless the patient is first-ever user or not. Patients using concomitantly low-dose aspirin and highdose nonaspirin NSAIDs are a subgroup of patients with 
a major increased risk of upper gastrointestinal complications.

\section{Abbreviations}

UGIB: Upper gastrointestinal bleeding; UGIC: Upper gastrointestinal complications; NSAIDs: Non-steroidal and anti-inflammatory drugs; RR; Relative risk; GPRD: General Practice Research Database.

\section{Additional material}

\section{Appendix 1}

[http://www.biomedcentral.com/content/supplementary/14726904-1-1-s1.doc]

\section{Appendix 2}

[http://www.biomedcentral.com/content/supplementary/14726904-1-1-s2.doc]

\section{Appendix 3}

[http://www.biomedcentral.com/content/supplementary/14726904-1-1-s3.doc]

\section{Appendix 4}

[http://www.biomedcentral.com/content/supplementary/14726904-1-1-s4.doc]

\section{Acknowledgements}

The authors wish to thank the general practitioners for their excellent collaboration. We also thank Dr. Sonia Hernández for her helpful comments, Dr. Antonio Salvador for his help in revising patients' profiles and the Boston Collaborative Drug Surveillance Program for providing access to the data. The validation of cases was in part supported by a research grant from Novartis.

\section{References}

I. Patrono C: Aspirin as an antiplatelet drug. N Engl J Med 1994, 330:1287-1294

2. Henry D, Lim LLY, García Rodríguez LA, Pérez Gutthann S, Carson JL, Griffin M, Savage R, Logan R, Moride Y, Hawkey C, Hill S, Fries JT: Variability in risk of gastrointestinal complications with individual NSAIDs. results of a collaborative meta-analysis. $\mathrm{Br}$ Med J 1996, 3 I 2:1563-1566

3. Weil J, Colin-Jones D, Langman M, Lawson D, Logan R, Murphy M, Rawlins M, Vessey M, Wainwright P: Prophylactic aspirin and risk of peptic ulcer bleeding. $\mathrm{Br}$ Med J 1995, 3 10:827-830

4. Kelly JP, Kaufman DW, Jurgelon JM, Sheehan J, Koff RS, Shapiro S: Risk of aspirin-associated major upper-gastrointestinal bleeding with enteric-coated or buffered product. Lancet 1996, 348:14|3-1416

5. Rowland M, Tozer TN: Clinical pharmacokinetics- concepts and applications. Lea \& Febiger, Philadelphia: I980,

6. Graham DY, Smith JL: Aspirin and the stomach. Ann Intern Med 1986, 104:390-398

7. Hoftiezer JW, Silvoso GR, Burks M, Ivey KJ: Comparison of the effects of regular and enteric-coated aspirin on gastroduodenal mucosa of man. Lancet 1980, 2:609-612

8. Lanza FL, Royer GL Jr, Nelson RS: Endoscopic evaluation of the effects of aspirin, buffered aspirin, and enteric-coated aspi- rin on gastric and duodenal mucosa. $N$ Engl J Med 1980, 303:136-138

9. Hawthorne AB, Mahida YR, Cole AT, Hawkey CJ: Aspirin-induced gastric mucosa damage: prevention by enteric-coating and relation to prostaglandin synthesis. Br J Clin Pharmacol 1991, 32:77-83

10. García Rodríguez LA, Hernández S: The risk of upper gastrointestinal complications among users of paracetamol and other non-steroidal antiinflammatory drugs. Epidemiology

II. García Rodríguez LA, Pérez Gutthann S: Use of the UK General Practice Research Database for pharmacoepidemiology. $\mathrm{Br} J$ Clin Pharmacol 1998, 45:419-425

12. Jick $\mathrm{H}$, Jick SS, Derby LE: Validation of information recorded on general practitioner based computerised data resource in the United Kingdom. Br Med J 1991, 302:766-768

13. García Rodríguez LA, Jick H: Risk of upper gastrointestinal bleeding and perforation associated with individual nonsteroidal anti-inflammatory drugs. Lancet. 1994, 343:769-772

14. Walker AM: Case-control studies: sampling the source population. In: Walker AM. Observation and Inference: An introduction to the methods of epidemiology. Chestnut Hill, MA: Epidemiology Resources Inc., 1991, 75-80

15. Pérez Gutthann S, García Rodríguez LA, Raiford DS: Individual nonsteroidal anti-inflammatory drugs and hospitalizations for upper gastrointestinal bleeding and perforation. Epidemiology. 1997, 8:18-24

16. De Abajo FJ, García Rodríguez LA, Montero D: Association between selective serotonin reuptake inhibitors and upper gastrointestinal bleeding: a population based case-control study. Br Med J 1999, 319:1 106-I 109

17. Rothman KJ: Modern Epidemiology, Ist ed, Little, Brown and Company, Boston: 1986,

18. Hosmer DW, Lemeshow S: Confidence interval estimation of interaction. Epidemiology 1992, 3:452-456

19. Ali M, McDonald JW, Thiessen JJ, Coates PE: Plasma acetylsalicylate and salicylate and platelet cyclo-oxygenase activity following plain and enteric-coated aspirin. Stroke 1980, I I:9-13

20. Wolfe MM, Lichtenstein DR, Singh G: Gastrointestinal toxicity of nonsteroidal antiinflammatory drugs. N Engl J Med 1999, 340:1888-1899

21. Lanza FL: A review of gastric ulcer and gastroduodenal injury in normal volunteers receiving aspirin and other non-steroidal anti-inflammatory drugs. Scand J Gastroenterol Suppl 1989, 163:24-31

22. Yood MU, Rothman KJ, Johnson CC, Jick S, Lang J, Wells KE, Jick H: Using prescription claims data for drugs available over-thecounter (OTC). Pharmacoepidemiology and Drug Safety 2000, 9 (suppl I):S37-

\section{Pre-publication history}

The pre-publication history for this paper can be accessed here:

http://www.biomedcentral.com/content/backmatter/ 1472-6904-1-1-b1.pdf

Publish with BioMedcentral and every scientist can read your work free of charge

"BioMedcentral will be the most significant development for disseminating the results of biomedical research in our lifetime." Paul Nurse, Director-General, Imperial Cancer Research Fund

Publish with BMc and your research papers will be:

- available free of charge to the entire biomedical community

- peer reviewed and published immediately upon acceptance

- cited in PubMed and archived on PubMed Central

- yours - you keep the copyright

Submit your manuscript here:

http://www.biomedcentral.com/manuscript/ 